УДК 37.012(47+57)(100)

\title{
РЕСУРСЫ ИНТЕГРАЛЬНЫХ ПОДХОДОВ В СФЕРЕ ОБРАЗОВАНИЯ В РОССИИ И ЗА РУБЕЖОМ
}

\author{
Гаськова Марина Ивановна, \\ mia78988@gmail.com
}

\begin{abstract}
Институт экономики и организации промышленного производства СО РАН, Россия, 630090, Новосибирск, пр. Академика Лаврентьева, 17.
\end{abstract}

Гаськова Марина Ивановна, кандидат социологических наук, научный сотрудник отдела социальных проблем Института экономики и организации промышленного производства СО РАН.

\begin{abstract}
Актуальность исследования связана с тем, что интегральная теория и интегральное образование являются новыми направлениями, разрабатывающимися в последние десятилетия. По этой причине в целом отмечается разобщённость исследователей, причём российские учёные, работающие в данной сфере, чаще всего неизвестны на Западе. Значимость статьи заключается в попытке преодоления фрагментарности знания, - как научного знания, сформированного мировоззрением классической науки, так и современной системы образования, дисциплинарной раздробленности, которая не способствует не только формированию целостной картины, но и гармоничному развитию здорового человека. Цель - обобщить и проанализировать основные подходы в сфере интегрального образования, существующие на данный момент в мире. Были использованы методы анализа, синтеза, классификации, сравнительного исследования. В результате была представлена «карта», систематизирующая основные подходы (разрабатываемые как отдельными исследователями, так и организациями) в мире, выделены ключевые черты, сильные и слабые стороны, главные истоки в развитии подходов, затронуты аспекты методов преподавания и методологии. Выводы. Интегральное образование затрагивает глубинные, сущностные основы в понимании процесса обучения. Оно способствует пересмотру главной идеи, составляющей содержание традиционного образования, условно выражаясь - «от информации к трансформации», т. е. от формального «перекачивания» информации из головы преподавателя в голову обучающегося к созданию условия для трансформации человека во всей его целостности. Студент больше не видится пассивным «получателем» знания, он активно вовлечён в процесс обучения с целью развития не только интеллектуальных (рациональных), но и ценностно-духовных, эмоциональных и социальных функций, формирования активной гражданской позиции, подразумевающей помощь ближнему и заботу об окружающей среде. Интегральное образование подразумевает обоюдное развитие преподавателя и обучающегося; признаёт существование разнообразия личностей учеников и учителей (стилей обучения, типов личности, педагогических стилей и пр.). С мировоззренческой, общечеловеческой точки зрения оно стремится способствовать межкультурному, межрасовому и межрелигиозному взаимопониманию и диалогу; признанию идеологического многообразия и единства человечества, сущностного равенства всех рас.
\end{abstract}

Ключевые слова: Интегральная теория, виды образования в мире, системная целостность, развитие и саморазвитие, формирование целостной личности.

В последние десятилетия в мире происходит формирование подходов, имеющих под собой общее основание, что позволяет некоторым исследователям говорить о новой парадигме научного знания. Стремление к целостному видению объекта исследования на основе обращения к разным научным дисциплинам является одной из основ- 
ных черт данного научного направления, которое некоторые российские исследователи относят к постнеклассической науке. Постнеклассическая наука избирает своим объектом «исторически развивающиеся системы с включённым в неё человеком» [1, с. 110]. «Человек интегрирован в подобную систему не фрагментарно, как, например, homo economicus, а тотально и непрерывно-бесконечно...» [1, с. 110].

Интегральные подходы, будучи основной составляющей постнеклассической науки, являются новой и формирующейся областью исследования во всём мире и не в последнюю очередь в России. Ключевым их аспектом является то, что они стремятся изучать человека в его целостности, учитывая как его внутренний мир, сознание, так и то, как оно проявляется и взаимосвязано с его физиологией, а также культурой, социальной структурой и материально-технической базой в развитии общества. Автор в течение последних пятнадцати лет стремилась сделать шаг в разработке и систематизации данной темы, применяя её к различным сферам знания.

В данной же работе хотелось бы затронуть одну из важнейших областей, связанных, в частности, с формированием сознания более молодых поколений и влияющих на многие сферы жизни общественного развития как в настоящее время, так и в будущем, - образованием. «Никогда ещё в истории не было настолько важным вкладывать в высшее образование как основную силу в построении открытого и приемлющего разнообразие общества знания, а также для продвижения исследований, инновации и творчества», - говорится в финальном тексте коммюнике Всемирной конференции по высшему образованию, организованной ЮНЕСКО [2, с. 124].

Главной предпосылкой появления интегральных подходов является высокая степень фрагментации научного знания, что отразилось и на образовательной системе. (Имея в своё время возможность учиться на разных специализациях общественных наук, автор статьи сталкивалась с парадоксальной ситуацией, где, к примеру, в зависимости от формальной дисциплины одного и того же учёного называли социологом, политологом или философом.) Раздробленность научного знания также сказывается на утере целостного представления о человеке. Данную проблему успешно решают рассматриваемые подходы.

Сам термин «интегральное образование» стал употребляться в сороковых годах (в США) [3]. Академический дискурс практически отсутствовал в основных течениях образовательной литературы, на ведущих конференциях и публикациях, касающихся холистически ориентированного, трансформативного или других видов прогрессивного образования, считает Ш. Эсбьорн-Харгенс (один из ведущих теоретиков данного направления). И только в течение последних лет эта ситуация стала меняться благодаря академическим публикациям, проведению различных семинаров и конференций, фокусирующихся на интегральном образовании [3]. В России же данное направление исследований разработано ещё меньше. К тому же, даже западные учёные, отмечают наличие высокой степени изолированности, отсутствие налаженной «сети» международного взаимодействия и контактов друг с другом. Всё это говорит о большом количестве «белых пятен» и работе, которую предстоит сделать в данной области.

Поскольку в исследовательской литературе иногда встречается употребление понятия «холизм», в т. ч. в применении к образованию, хотелось бы далее затронуть вопрос терминологии и некоторых методологических аспектов, представляющихся значимыми для рассматриваемой в статье проблематики, а именно сходствам и различиям в понимании холистического и интегрального образования.

С общефилософской точки зрения сходным между основными принципами интегральных подходов и холизмом является то, что «холистическое мировоззрение активно 
противопоставляет образу мира как суммы изолированных вещей взгляд на мир как единство кооперированных и интегрированных объектов [4, с. 3]. В конце XVIII-XIX вв. идеи холизма развивались как оппозиция картезианской парадигме, а в XX в. - в русле системного мышления. В различных предметных областях науки разрабатываются идеи нередуцируемой целостности - целостность атомного и субатомного мира, целостность восприятия (гештальтпсихология), взаимообусловленность элементов различных сообществ (теории автопоэза, «глубокая экология» А. Наэсса, Гея-концепция, теории экологического эголитаризма и др.) [4].

Те же идеи применимы и к сфере образования: ключевой чертой интегрального образования является то, что оно стремится к обучению человека во всей его целостности, а не к формальной передаче ему определённого набора знаний или только «натаскиванию» к некоторым практическим навыкам. «Мы не просто подготавливаем людей к тому, чтобы заполнить вакантные места на рынке труда... Мы обучаем человеческую личность в целом» $[5$, с. 332].

В англоязычной литературе по данному вопросу используется образное выражение «пустого котелка», которое, как представляется, удачно передаёт основной подход традиционного образования к обучающемуся: процесс обучения видится как «переливание» информации от преподавателя к студенту, который пассивно её впитывает. Интегральное же образование подразумевает и старается создать возможность для трансформации всей личности человека. «Во-первых, интегралисты считали, что образование должно затрагивать человеческое существо в его целостности; оно должно включать в себя физическое, эмоциональное, ментальное и духовное. Во-вторых, оно должно быть глобальным и учитывать «ситуацию человечества во всей её совокупности», писал Харидас Чаудхури, один из основателей Калифорнийского института интегральных исследований и идейных вдохновителей интегрального образования [6, p. 78]. Также образование должно стремиться к тому, чтобы преодолеть противоречия и антагонизмы, внутренне присущие культурным и философским установкам обычного человека [7, p. 48]. Полагаю, есть основания выделить данные признаки в качестве главных ценностей интегрального образования. Интегральный подход затрагивает глубинные, сущностные основы понимания образования.

Существует мнение, согласно которому холистическое образование в большей степени, чем интегральное склонно к идеализированному акцентированию субъективных, внутриличностных аспектов развития и значимости сплочённости учебного коллектива [8, p. 303]. Первоначально (в качестве эксперимента) в Холма колледже холистических исследований в Швеции (Holma College of Holistic Studies) акцент делался на холистическом образовании, но позже руководство пришло к выводу, что интегральное образование является более сбалансированным и гармоничным [8]. Оно фокусируется как на субъективном, так и на интерсубъективном и объективном аспектах [9].

В целом необходимо отметить, что не существует единого общепринятого мнения относительно употребления обсуждаемых терминов: некоторые считают их синонимичными, а некоторые нет. Наиболее же взвешенной представляется точка зрения, согласно которой невозможно провести чёткого разграничения между интегральным и холистическим образованием «на основе исторических фактов, мировоззрения, преследуемых целей или применяемых методов» [10, с. 319]. М. Молтс также полагает, что холистическое образование имеет комплексное мультирегиональное происхождение: «Это в большей степени собирательный термин, включающий в себя несколько направлений, чем чётко определённый подход к образованию» [10, с. 319]. В некоторых центрах холистического образования основные подходы к обучению совпадают с тако- 
выми в учреждениях, придерживающихся интегрального образования, а в других - отличаются [10]. (Имеет смысл добавить, что в России, насколько известно автору данной статьи, не существует чётких разграничений и дискуссии по данному поводу.)

Говоря о конкретных подходах, которые являются сегодня основой того, что понимается под интегральным образованием в западных организациях, рассмотрим идеи Шри Ауробиндо и работы современного американского учёного Кена Уилбера. К. Уилбер создал всеобъемлющую теорию, дающую возможность глубоко и всесторонне исследовать разнообразные феномены жизни и оказавшую наибольшее влияние на западную мысль в сфере подходов, стремящихся к целостности в последние десятилетия. Ключевой составляющей в его теории является модель AQAL, означающая «все квадранты, все уровни, все линии, все состояния и все типы». Модель даёт возможность исследовать внутренние и внешние аспекты жизни индивида и общества, как сознание, так и социальные, экономические, политические и другие факторы. Одновременно с этим она учитывает «вертикальный» срез, т. е. перспективу в развитии (эволюции) указанных факторов. Более детально сущность подхода рассматривала и автор статьи в своих предыдущих работах на протяжении последних 15 лет, применяя его к различным областям знания и считая его действительно значимым и дающим возможность действительно внести новый вклад в современные науки о человеке и обществе.

Идеи интегрального подхода (и в том числе в сфере образования) применяются в разнообразнейших областях знания - помимо наук о человеке и обществе это точные науки, бизнес и даже такие сферы, как медицина и музыка.

Возвращаясь к другим значимым аспектам обсуждаемого вопроса, хотелось бы отметить, что интегральное образование восполняет один из главных недостатков современной системы образования в «общефилософском» его смысле. Он заключается в излишнем акценте на развитии рациональности в ущерб духовным, эмоциональным, нравственным сторонам человека, его способности помочь ближнему, заботе о планете и пр., т. е. в утере целостной картины индивида [11-13]. Обсуждаемый вид образования также способствует глубинному осознанию осмысленности своей деятельности, когда «наиболее глубоко переживаемые ценности признаются и уважаются» [5, с. 335].

А если затрагивать вопрос взаимосвязи интегрального образования с одной стороны и социально- политических и экономических аспектов общественной жизни с другой, некоторые авторы отмечают, что первое из указанных позволяет восполнить недостатки современных западных общественных систем, являющихся материалистическими и основанными на получении экономической прибыли. Традиционное образование, будучи зачастую утилитарным, способствует укреплению данных ценностей. Творческие же импульсы человека становятся всё более зависимыми от законов рыночной экономики [2]. А некоторые даже полагают, что «будущее демократий висит на волоске, так как нации по всему миру будут вскоре производить поколения полезных машин, а не всесторонне развитых граждан своих стран, которые могут нести ответственность за свои решения, критиковать традицию и понимать значимость страданий и достижений другого человека» [14, с. 2].

Возвращаясь к вопросу ключевых аспектов интегрального образования, хотелось бы также отметить в нём особую значимость дисциплин, направленных на служение обществу (service-learning) [15]. Б. Якоби определяет данную дисциплину как «форму практически ориентированного образования, в которой студенты вовлекаются в деятельность, адресованную человеческим и общественным нуждам, одновременно с этим имея возможность для рефлексии и достижения желаемого результата в обучении» $[16$, c. 28]. Получающее всё большее развитие в структуре американского образования, 
оно полностью отсутствует в российском, тем не менее будучи несомненно полезным как для общества, так и для студента. (В России волонтёрские движения, а также деятельность различных религиозных деноминаций в некоторой степени стали восполнять данный пробел в последние десятилетия.)

Эсбьорн-Харгенс выделил десять основных характеристик интегрального образования (одновременно с этим представляется важным отметить, что он не считает их исчерпывающими и взаимоисключающими) [9].

Это, во-первых, использование различных исследовательских перспектив (интегральный методологический плюрализм). Автор данной статьи полагает, что данная характеристика - одно из наиболее значимых «приращений» для современных наук о человеке и обществе с методологической точки зрения. Если в России сегодня особую актуальность получили междисциплинарные исследования, то интегральная теория идёт дальше - она создаёт основания для взаимодействия различных дисциплин, одновременно с этим помогая определить как ограничительные рамки каждой, так и новые возможности, возникающие в результате интеграции. Как западные, так и российские учёные полагают, что применительно к современным холистически направленным подходам уместно говорить о постметодологии и постдисциплинарности. «Стоит уточнить, что сама проблема постметодологии связана с поиском преодоления неизбежного редукционизма любых методологий, традиционно реализующихся в методах, призванных поддерживать иллюзию объективации» [17, с. 12]. Применительно к психологическим дисциплинам «интегральная модель является: постдисциплинарной в том смысле, что она может быть успешно использована в контексте дисциплинарности (т. е. помогать интегрировать различные школы психологии в интегральную психологию); мультидисциплинарной (т. е. помогать исследовать вопросы экологии с точки зрения разных дисциплин); междисциплинарной (т. е. помогать применять методы политической науки к психологическим исследованиям); трансдисциплинраной (т. е. помогать различным дисциплинам и их методологиям взаимодействовать без установления жёстких рамок» $[18$, с. 73$]$.

Во-вторых, это признание одновременного существования и взаимодействия субъективных, интерсубъективных и объективных аспектов реальности (методологии преподавания и обучения от «первого, второго и третьего» лица) и поддерживание взаимодействия с ними на основе определённых критериев. Для этого часто используются художественное творчество, исследования, основанные на активной вовлечённости в насущные проблемы общества (participatory inquiry), эмпирический анализ и пр. Предпоследний из упомянутых вид исследований, насколько известно автору статьи, на сегодняшний день является практически полной terra incognita для российских наук о человеке и обществе. В целом обследования, сущностью которых является широкая вовлечённость исследуемых респондентов (participatory research), «включают в себя различные методологические подходы и техники, цель которых заключается в передаче большей власти от исследователя тем, кто принимает в них участие. Чаще всего, это члены местной общественности или местных общественных организаций. В подобном виде исследований их участники имеют контроль над изучаемыми вопросами, процессом и действиями. Наиболее же важно то, что люди сами анализируют и осмысливают полученную информацию для получения результатов исследовательского процесса» [19]. Учёные отмечают, что данные методы отличаются от более традиционных тем, что в последних подчёркивается безучастность исследователя и воспроизводимость результатов [20]. 
В-третьих, интегральные подходы стремятся учитывать аспекты культуры, природы и самости человека. В-четвёртых, они не являются сугубо теоретически ориентированными, а учитывают индивидуальный опыт переживания. В-пятых, в них учитывается тот факт, что люди находятся на разных этапах развития (в т. ч. используются идеи возрастной психологии). В-шестых, данные подходы включают в образовательную программу практики, способствующие трансформации. В-седьмых, как уже упоминалось, интегральные подходы стремятся к развитию в индивиде всесторонней личности, во всей её целостности, как имеющей тело, сердце, разум, душу и дух (когнитивная, эмоциональная, моральная, кинестетическая и другие линии развития). В-восьмых, подходы признают, что существуют различные типы учеников и учителей (стили обучения, типы личности, педагогические стили и пр.).

В-девятых, в них поощряется работа «с собственной тенью»: обучаясь видеть в себе (и в других) то, что нам не хочется, мы становимся более сострадательными и открытыми новому. Ш. Эсбьорн-Харгенс отмечает, что в процессе работы их коллектив убедился, насколько важно «уметь избавляться от собственных проекций, минимизировать идеализацию, брать на себя ответственность и прочее. Как учителям, так и студентам полезно научиться понимать свои «чувствительные точки», которые могут вызвать в них бурную реакцию или способствовать тому, что они замыкаются в себе, становятся пренебрежительным и тому подобное». [9, с. 9]. И наконец, интегральный подход подразумевает равноценную значимость других (традиционных, альтернативных, холистических) подходов в образовании.

В целом с мировоззренческой, общечеловеческой точки зрения интегральное образование стремится способствовать межкультурному, межрасовому и межрелигиозному взаимопониманию и диалогу; признанию идеологического разнообразия и единства человечества и сущностного равенства всех рас, народов и наций на Земле, писал один из основателей данного течения Х. Чаудхури [7].

Далее хотелось бы затронуть конкретные организации, где применяются и развиваются интегральные подходы (в образовании), а также «географию» его распространения в мире. Ведущий на сегодня подход, основанный на работах современного американского учёного К. Уилбера, наиболее институционализирован в США, где существует несколько высших учебных заведений, внедряющих его, а также и другие близкие к нему подходы, применяемые в течение последних десятилетий. (К таковым относятся Калифорнийский институт интегральных исследований, Интегральный институт, Институт трансперсональной психологии, Университет Дж.Ф. Кеннеди и др.) Также каждые два года Университетом Дж.Ф. Кеннеди организуется конференция. В США (как и в других западных странах) существуют академические журналы, фокусирующиеся на интегральных подходах.

М. Молтс в одной из своих статей делает обзор современной ситуации в сфере интегрального и смежных с ним областей образования в мире [10]. Что касается холистического образования, существует международное сообщество - «Холистическое образовательное сообщество в сфере обучения и духовности» (“Holistic Learning and Spirituality in Education Network”), координируемое Джэком Миллером, одним из ведущих исследователей в этой области. Данная организация также регулярно участвует в крупной международной конференции, вовлекающей большое количество участников со всего мира. Существует к тому же «Тасманийское сообщество холистического образования», в котором проходит обсуждение принципов и практики данного вида образования. В Мексике Рамон Галлегос Нава (Ramón Gallegos Nava), написавший более десяти книг по холистическому образованию, в 1992 г. создал «Международный фонд 
холистического образования», предоставляющий различные обучающие программы и организующий конференции в данной сфере.

Индиец Прабхат Ранджан Саркар (Prabhat Ranjan Sarkar, 1921-1990), будучи человеком широчайшей эрудиции и разностороннего развития, является автором исследований в многочисленных областях знания от макроистории до йоги; он также был социальным реформатором, композитором и духовным учителем. Саркар основал направление неогуманистического образования и создал социально-духовную организацию «Ананда Марга», деятельность которой распространилась по всему миру. Одно из отделений этой организации, занимающееся образованием, координирует работу более тысячи детских садов, школ и колледжей в более чем 50 странах мира. Его видение образовательного процесса и практики получило своё дальнейшее развитие в академической среде.

Сегодня также существует антропософское направление в образовании на Западе. Рудольф Штайнер основал Гетеанум в Швейцарии, являющийся центром Антропософского сообщества. Там есть и педагогическая секция, реализующая проекты по исследованию, развитию и поддержке образовательной практики. Также функционирует Исследовательский институт образования по системе Вальдорф (Research Institute for Waldorf Education). Система Вальдорф основана на идеях Р. Штайнера, в которой выпускается научный бюллетень, систематизирующий исследования в транснациональной перспективе [21]. Существуют также магистерские программы для практикующих учителей в Университете Плимута в Великобритании.

Образовательная же школьная система Вальдорф получила международное признание. Первая школа открылась в Штутгарте, Германии, в 1919 г. и через столетие разрослась до крупнейшей независимой сети в мире, включающей в себя около 1200 школ, 1800 детских садов и 646 центров специального образования, расположенных в 75 странах. Открыты также другие виды образовательных организаций в данной системе (академии, обучение на дому и пр.). Главными их целями является создание такой почвы, на которой дети могут «вырасти в свободных, морально ответственных, творчески развитых и целостных личностей». Однако независимых исследований относительно того, насколько результативны поставленные цели, пока неизвестны [22].

Также М. Молтс в упомянутой выше статье [10] отмечает такое направление в современных подходах к образованию, как трансдисциплинарное, распространённое преимущественно на юге Европы и Южной Америке. В первую очередь здесь необходимо отметить социолога Эдгара Морина (Edgar Morin), почётного директора престижного Французского национального исследовательского института (CNRS). Э. Морин за 60-летний период исследовательской работы оставил большое наследие из публикаций, включающих и тему образования. Басараб Николеску (Basarab Nicolescu) и Э. Морин в 1994 г. составили хартию принципов трансдисциплинарности. Николеску - создатель и координатор Международного центра трансдисциплинарных исследований (CIRET). Он занимался исследованиями в отношении применения принципов трансдисциплинарности к образованию и вдохновил некоторых исследователей, занимающихся вопросами образования, к дельнейшему развитию идей в указанном направлении.

В 1998 г. в Бразилии был открыт Центр трансдисциплинарного образования (CETRANS). Его члены работают в различных профессиональных областях и проживают в Южной и Северной Америке, а также в Европе. Центр реализует исследовательские проекты в сфере образования и организует конференции.

M. Молтс в упомянутой выше статье выделяет также работы Роя Бхаскара (Roy Bhaskar) и направление критического реализма, в котором автор пытается преодолеть 
ограничения модернизма и постмодернизма, обратившись к философии метареальности и духовной сфере. Идеи Бхаскара получили свою институционализацию (существует Международная ассоциация критического реализма, а также ежегодно организуются конференции и издаются печатные работы). Они также послужили плодотворной почвой для многих других исследователей, в том числе в сфере образования.

В рамках немецкой Комиссии по гуманистической психологии и педагогике работает ряд сторонников интегрального подхода в образовании. Ключевыми фигурами в Западной Европе являются Генрих Даубер (Heinrich Dauber), Джозеф Кёйфер (Josef Keuffer), Трауготт Эльзасcеp (Traugott Elsässer), Ральф Гирг, Хаген Кордес (Hagen Kordes), Регина Микула (Regina Mikula), Даниэла Михаэлис (Daniela Michaelis), Нильс Алтнер (Nils Altner), Юрген Эльшольц (Jürgen Elsholz) и Маркус Молз (Markus Molz). Некоторые исследователи (включая автора данной статьи) черпают полезные ресурсы также и в буддистской философии: Вольфганг Ротт (Wolfgang Roth), почётный профессор психологии, был организатором академической конференции «Наука и духовность - новые перспективы в образовании», идейным вдохновителем которой был Далай-лама в 2007 г., а также проходящих и по сей день мероприятий, связанных с данной темой. Профессор Дж. Кёйфер написал в своё время диссертацию на тему буддизма и образования в сравнительной перспективе.

Данный список, конечно, не является исчерпывающим - хотелось только затронуть ключевые направления. Представлялось важным уделить им внимание по той причине, что, как уже упоминалось, данное направление исследований является новым и слабо институционализированным, а учёные крайне разобщены. Поэтому актуальной на сегодняшний день является необходимость налаживания взаимодействий и международного сотрудничества. В особенности это важно для российских учёных, которых единицы, но даже они неизвестны за рубежом: к примеру, в указанной выше обзорной статье Молтса [10] современные российские учёные не упомянуты вообще!

Данный факт, конечно, не означает, что в России сегодня нет исследователей, работающих в русле целостного подхода. Из современных направлений в первую очередь хотелось бы отметить школу ноэтических исследований и работы преподавателей философского и психологического факультетов Томского государственного университета (доктора философских наук И.В. Черникова, теорию транскоммуникации доктора психологических наук В.И. Кабрина и других исследователей). Также, к таковым относится универсумная социология В.Г. Немировского (Красноярский государственный университет). Нельзя не упомянуть различные ответвления синергетики - одного из ключевых направлений постнеклассической науки в России (например, работы В.В. Васильковой). Также это социосинергетика (Е.Н. Князева, Е.Я. Режабек, В.П. Бранский); синергетика истории (С. Гомаюнов); синергетика культуры (М.С. Каган); холистскоэмерджентная или синергетически-эволюционная теория (В. Аршинов, В. Буданов, А. Суханов и др.). (Нельзя, однако, утверждать, что все они применяют данные подходы к сфере образования.)

Из молодых российских последователей интегрального подхода необходимо отметить Евгения Пустошкина, выпускника СПбГУ, главного редактора онлайн-журнала «Эрос и Космос», переводчика работ западных ведущих теоретиков в этой области, психолога. Е. Пустошкин сотрудничает с Александром Малаховым из Хабаровска, редактором данного журнала. Это единственные исследователи сегодня в России (известные автору статьи), которые основываются непосредственно на теории Кена Уилбера в своей работе. 
Поскольку системный подход и синергетика достаточно распространены в России, делаются попытки применить их и в образовании, в частности в работе П.А. Стрельникова и Л.С. Зникиной [23]. Одним из ключевых понятий в данной статье является интегративная образовательная компетенция, интерпретируемая как «совокупность образовательных компетенций, результат сформированности которых определяет уровень профессиональной готовности и социальной адаптации выпускников» [23, с. 41]. Авторы выстраивают взаимосвязи между основными характеристиками системного подхода и того, как его можно применить к педагогике России сегодня. Однако эти взаимосвязи создают ощущение некоторой «искусственности» в указанной работе и не затрагивают глубинной сути процесса обучения: «Формирование интегрированной совокупности компетенций, таким образом, не предусматривает наличия интеграционной основы - какой-либо базовой компетенции или учебного курса - поскольку интегрируемые компоненты объединяются посредством цели деятельности» [23, с. 41]. Стоит отметить одновременно с этим, что сфокусированность на «внешних» социальных сетях и недостаточное внимание «внутренним» (личностным, культурным и другим) аспектам развития является как раз характеристикой самого системного подхода и, возможно, поэтому нет особых оснований видеть в этом слабые стороны непосредственно данной статьи.

А.И. Тимошенко в своей монографии также использует синергетический подход, разработав методологию построения интегрированных курсов и предлагая три уровня их интеграции (технологический, коммуникативный и пространственно-предметный) [24].

Несомненно, что некоторые современные российские исследователи признают значимость и актуальность интегративных процессов в современном образовании. «Предрасположенность образовательной системы к интеграционным процессам определяется глобализацией научных, производственных и экономических задач, тенденцией к обобщению, уплотнению научной информации, росту емкости и системности знаний» [25, с. 9]. «В настоящее время в отечественном социогуманитарном познании продолжается активный процесс формирования интегративной науки об образовании, подчиняющейся общим законам интеграции и дифференциации научного знания», пишет Т.А. Арташкина в статье «Основные стратегические направления интегративной науки об образовании» [26, с. 5]. Однако, как уже было упомянуто, исследования в обсуждаемом направлении находятся в «зачаточном» состоянии и являются задачей для предстоящей работы в будущем. Несмотря на многообещающее название данной статьи, её автор, к сожалению, не формулирует и не основывается ни на какой единой концепции интегративной науки об образовании, не выводит никаких основных её принципов. Т.А. Арташкина скорее рассматривает актуальные проблемные аспекты современного образования и общества общего характера. Тем не менее представляется, что они имеют свою значимость, в том числе и для интегративных направлений исследований в России, учитывая особенности развития системы образования в нашей стране. В частности, Т.А. Арташкина поднимает вопрос выпадения концепции воспитания из образовательной концепции в 90-е годы XX в. Школа (это можно отнести и к высшей школе) стала преимущественно обучающим учреждением, дающим сугубо интеллектуальные или практические навыки. Автор также поднимает вопрос формирования и трансляции прерванных духовных и культурных ценностей в связи с периодом Советского времени, где были сделаны попытки сформировать «нового» советского человека; это проблема сохранения личности в социокультурном пространстве современного глобального мира, в котором человек испытывает повышенное воздействие информационных потоков и другие. 
Нельзя, конечно, утверждать, что перечисленные работы и направления исследований российских и западных учёных идентичны в своём подходе. Однако в них есть общие характеристики, которые представляются ключевыми. Главным (помимо перечисленных в начале статьи основных аспектов) представляется то, что с философской точки зрения в их основе лежит видение мира как системной целостности, включающей в себя сознание индивида.

Хотелось бы также ещё раз затронуть значимый вопрос о методах преподавания, (поднимаемый и российскими исследователями): «условия организации интегративной образовательной среды не должны допускать традиционной учебной ситуации, когда обучающийся остается пассивным потребителем. Коммуникативный компонент интегративной образовательной среды техникума предполагает широкое использование проблемных, эвристических методов обучения, проведения деловых игр, выполнение междисциплинарных научно-исследовательских проектов и т. п. [27]. Западные преподаватели также просят студентов вести дневник (к примеру, на курсах интегральной психологии), быть максимально открытыми к обратной реакции; они не игнорируют живое общение и т. д. Главная идея заключается в том, чтобы задействовать человека во всей его целостности, а не «натаскать», к примеру, инструментально на профессию или способствовать развитию только интеллектуальных функций. Концепцией интегративной образовательной среды является модель развивающего образования, ведущие ценности которой - развитие и саморазвитие всех субъектов образования и самого образовательного процесса (образовательной деятельности) в режиме взаимосодействия [28].

Хотелось бы также отметить, что существуют и «нестандартные» интегративные подходы, в которых в качестве ключевой компоненты выделяется какая-либо характеристика, не играющая существенной роли в теории К. Уилбера и в большинстве других подходов. К примеру, в статье «Образовательный дуализм и секуляризм: интегративный подход к образовательной системе в Уганде» Муса Матову [29] подчёркивает, что образование не может быть интегративным без учёта национальной образовательной философии, а именно значимости ислама для нации. Исторической особенностью Уганды, утверждает автор, являлось то, что колониальное правительство всячески подавляло мусульман и пыталось насадить христианство под видом необходимости отделения религии и государства, отличалось борьбой с идеей государственной религии и пропаганде идей секуляризации. Однако, как полагает автор, «в то время как видение сущности образования в Уганде непосредственно связано с развитием человека и нации в холистическом и интегративном ключе, существует необходимость в интегративной образовательной системе для воспитания индивидов, которые интеллектуально, духовно, эмоционально и физически здоровы благодаря явленному знанию» [29, с. 123].

Шелли Маккеон в своей работе [30] также рассматривает вопрос о значимости религиозного и национального факторов для интегративного образования, но совсем в другом ракурсе. Автор доказывает тезис о важности совместного обучения школьников, родители которых принадлежат к разным религиям и национальностям в обществе, столетиями переживающем конфликты высокой степени на данной почве (Северная Ирландия). Конфликты между католиками и протестантами, продолжающиеся там несколько веков, «имеют разрушительные последствия на все стороны североирландского общества. Согласно приблизительным оценкам, около 3600 людей было убито и более 30 тыс. травмировано с 1968 по 1998 г. Сегрегация находится на высоком уровне, большинство детей посещают религиозно сегрегированные школы и почти 40 \% жилых районов являются сегрегированными по религиозному признаку, причём этот показа- 
тель является ещё более худшим в областях с низким социально-экономическим статусом» $[30$, c. 80$]$.

Поэтому одним из выходов из данной ситуации автор видит в интегрированном образовании как средстве для установления мирных и гармоничных отношений и для исключения дискриминации. Под интегративным, смешанным или инклюзивным образованием Ш. Маккеон подразумевает такой вид образования, в котором дети и молодежь, принадлежащие к семьям, имеющим разное расовое или религиозное происхождение, обучаются вместе [30]. Рассматриваемые в указанной статье результаты эмпирического исследования, проводимого в течение 11 лет в масштабе всей страны, показали, что подобное обучение является благоприятным в решении описанных проблем. Молодые люди, посещавшие интегрированную школу, в большей степени, чем ученики сегрегированных школ склонны к тому, чтобы проживать, работать и отдавать своих детей в организации с людьми, принадлежащими к разному религиозному вероисповеданию.

Нельзя утверждать, что две последние работы можно в полном смысле слова отнести к интегративным подходам, рассматриваемым в статье. Данные исследования вообще не затрагивают вопросы методологии или метатеории - их, скорее, можно отнести к «теориям среднего уровня», выражаясь социологическим языком. Однако представлялось значимым затронуть обсуждаемые работы в данной статье не только по той причине, что для них важны вопросы целостности, но также и потому, что авторы анализируют крайне значимый вопрос, не рассматриваемый чаще всего в других работах интегративного направления, включая работы самого К. Уилбера. Он касается вопросов специфики развития определённой нации и её менталитета (включая религиозность). Одна из исследовательских проблем, которая существует в данном ключе, состоит в том, насколько правомерно обобщать основные принципы интегрального подхода и применять их к конкретной стране, какова степень его универсализации, если можно так выразиться. К примеру, негласным положением К. Уилбера (ведущего теоретика и создателя интегральной теории) является то, что современные западные демократии более прогрессивны, чем, к примеру, то же традиционное общество Уганды, проблемы которого затронуты выше. В каком-то смысле, можно было бы считать предвзятым мнение Мусы Матову, что образование должно непременно включать в себя обучение исламу. Но, с другой стороны, возможно рассматривать эту ситуацию и в таком ключе, что религиозный аспект крайне важен в традиционном обществе, это очень значимый элемент, отвечающий за его стабильность, целостность. Однако этого и не отрицают интегральные подходы.

Представляется, что на основе затронутых выше статей можно было бы выдвинуть гипотезу, что в определённом смысле каждая культура по-своему видит и конструирует представления о целостности, в соответствии со своим «культурным кодом», но это уже было бы объектом исследования в другой работе.

Ещё в одном интегральном подходе Т.В. Фрика, касающегося разрабатываемой теории целостного интегрированного образования, автор фокусируется в большей степени на ментальных аспектах обучения, выделяя в качестве ключевых целостность и гибкость системы в процессе познания [31]. Фрик предполагает, что деятельность по обучению, которая увеличивает целостность в ментальных структурах обучающегося, является более эффективной для процесса запоминания. Целостное интегрированное образование должно максимизировать интеграцию между видами знания (познания), намерения (способность к целенаправленному действию) и чувствам (эмоциям) и повысить внутреннюю взаимосвязь и степень развитости ментальных структур, утвер- 
ждает автор. Наиболее значимым представляется то, что Т.В. Фрик уделяет особое внимание эмоциональному фактору в процессе обучения и поддержания интереса к предмету (что играет особую роль при изучении иностранного языка, о чём писала автор данной статьи в другой своей работе). Обучение, проходящее в процессе целостного интегрированного образования, должно приводить к более стабильной долговременной памяти и меньшей уязвимости ментальных структур, убеждён Т.В. Фрик.

Итак, если задаться вопросом о том, каким могло бы быть определение интегрального образования, к какому «образу» стремиться, то представляется, что оно близко к следующему: это обучение человека (во всей его целостности и с учётом множественности перспектив), которое способствует развитию всех способностей, не подавляя и не пренебрегая ни одной из них. Формирование личности студента, способствующее его/её преданности идеям ответственного гражданства, способного жить в плюралистическом и взаимозависимом мире; такое образование, от которого требуется быть намного более всеохватывающим в сравнении с тем, которое максимизирует прибыль и формирует жизненный идеал успешной жизни, где деньги и власть являются единственным мерилом успеха [2].

Таким образом, в данной статье была сделана попытка воссоздать «карту мира» интегральных подходов в образовании, систематизирующую достаточно широкий спектр авторов и исследовательские институты из множества стран. К таковым относятся преимущественно европейские, а также северо- и южноамериканские государства. Тем не менее теоретические истоки подходов восходят и к восточным учениям. Также, говоря о восточных странах, большое значение имеют регулярно проводимые международные конференции по вопросам образования, вдохновлённые Далай-ламой $\mathrm{XIV}$ и при его участии. Автор статьи стремилась уделить особое внимание ситуации в России как наименее известному региону для иностранных учёных.

Были также выделены основные черты интегральных подходов в образовании. В первую очередь в их основе лежит видение мира как системной целостности, включающей в себя сознание индивида. Также интегральное образование стремится к гармоничному, целостному обучению, включающему в себя эмоциональные, духовные аспекты, формирование гражданской ответственности, а не только развитие интеллектуальных функций или «натаскивание» к определённым навыкам. Поощряется активность обучающегося, его развитие, как и развитие всей образовательной среды в противовес традиционного видения процесса образования, где предполагается, что знания «перекачиваются» из головы преподавателя в голову студента, занимающего преимущественно пассивную позицию. В основе тех подходов, которые опираются на определяющую в данном направлении теорию современного американского учёного К. Уилбера, лежат концепция о поэтапных стадиях в развитии индивида/общества, убеждение в признании «равноправия» каждой из них как необходимой и одновременно с этим стремление к росту. Интегральное образование также уделяет большое внимание диалогу, оно открыто другим методам, демократично, предполагает всеохватывающий, гуманистический, а не узкоутилитарный подход.

Статья подготовлена в рамках государственного задания ФАНО России по проекту ХІ.179.1.2. «Условия и стимулы формирования и реализации человеческого потенциала населения в трудовой и образовательной сферах» № АAАA-A17-117022250119-3. 


\section{СПИСОК ЛИТЕРАТУРЫ}

1. Тарасевич В. Постнеклассический вызов фундаментальной экономической науке // Вопросы экономики. - 2004. - № 4. - С. 107-117.

2. Bertolin J. Higher education and development in the knowledge society: from integral education to substantial positive externalities // Higher Education for the Future. - 2018. - V. 5 (2). - P. 122-141.

3. Esbjörn-Hargens S. Integral teacher, integral students, integral classroom: applying integral theory to education. URL: http://nextstepintegral.org/wp-content/uploads/2011/04/Integral-Education-Esbjorn-Hargens.pdf (дата обращения 14.05.2019).

4. Оболкина С.В. Онтологическая грамматика холизма как философская проблема: автореф. дис. ... канд. филос. наук. - Екатеринбург, 2005. - 26 с.

5. Astin A., Reams J. Spirituality and integral thought in higher education // Integral Education. New Directions for Higher Learning / Ed. by S. Esbjörn-Hargens, J. Reams, O. Gunnlaugson. - New York: SUNY Press, 2010. - P. 331-344.

6. Chaudhuri H. The evolution of integral consciousness. - Wheaton, Ill.: Theosophical Pub. House, 1977. $140 \mathrm{p}$.

7. Ryan J. The complete yoga: the lineage of integral education // Integral Education. New Directions for Higher Learning / Ed. by S. Esbjörn-Hargens, J. Reams, O. Gunnlaugson. - New York: SUNY Press, 2010. - P. 47-56.

8. Gunnlaugson O. Opening up the path of integral education // Integral Education. New Directions for Higher Learning / Ed. by S. Esbjörn-Hargens, J. Reams, O. Gunnlaugson. New York: SUNY Press, 2010. - P. $303-316$.

9. Esbjörn-Hargens S., Reams J., Gunnlaugson O. The emergence and characteristics of integral education: an introduction // Integral Education. New Directions for Higher Learning / Ed. by S. Esbjörn-Hargens, J. Reams, O. Gunnlaugson. - New York: SUNY Press, 2010. - P. 1-16.

10. Molz M. Contemporary integral education research: a transnational and transparadigmatic overview // Integral Education. New Directions for Higher Learning / Ed. by S. Esbjörn-Hargens, J. Reams, O. Gunnlaugson. - New York: SUNY Press, 2010. - P. 317-330.

11. Ferrer J., Romero M., Albareda R. Integral transformative education: a participatory proposal // Integral Education. New Directions for Higher Learning / Ed. by S. Esbjörn-Hargens, J. Reams, O. Gunnlaugson. New York: SUNY Press, 2010. - P. 79-104.

12. Hocking B., Haskell J., Linds W. Unfolding bodymind: exploring possibility through education. - Rutland, VT: Foundation for Educational Renewal, 2001. - 180 p.

13. New directions in education: selections from holistic education review / Ed. by R. Miller. - Brandon, VT: Holistic Education Press, 1991. - 365 p.

14. Nussbaum M.C. Not for profit: why democracy needs the humanities. - Princeton, NJ: Princeton University Press, 2016. - $192 \mathrm{p}$.

15. Torosyan R. Teaching integratively: five dimensions of transformation // Integral Education. New Directions for Higher Learning / Ed. by S. Esbjörn-Hargens, J. Reams, O. Gunnlaugson. - New York: SUNY Press, 2010. - P. 127-148.

16. Jacoby B. Service-learning in higher education: concepts and practices. - San Francisco: Jossey-Bass, 1996. $-416 \mathrm{p}$.

17. Кабрин В.И. Транскоммуникативные основания анализа ценностного мира человека // Ценностные основания психологической науки и психология ценностей / под ред. В.В. Знакова, Г.В. Залевского. - М.: Институт психологии РАН, 2008. - С. 186-215.

18. Esbjörn-Hargens S. Integral theory in service of enacting integral education: illustrations from an online graduate program // Integral Education. New Directions for Higher Learning / Ed. by S. Esbjörn-Hargens, J. Reams, O. Gunnlaugson. - New York: SUNY Press, 2010. - P. 57-78.

19. Participatory Research Methods. URL: http://participatesdgs.org/methods/ (дата обращения 08.07.2019).

20. Participatory Action Research. URL: https://en.wikipedia.org/wiki/Participatory_action_research\#cite_noteChevalierBuckles2013-2 (дата обращения 08.07.2019).

21. Nordwall S. What studies have been published on Waldorf education? URL: www.waldorfresearchinstitute.org/pdf/RCWaldorfRes.pdf (дата обращения 08.07.2019).

22. Waldorf Education. URL: https://en.wikipedia.org/wiki/Waldorf_education (дата обращения 10.07.2019).

23. Стрельников П.А., Зникина Л.С. Принципы системно-функционального развития интеграционных образовательных процессов // Вестник КемГУ. - 2017. - № 4. - С. 41-44.

24. Тимошенко А.И. Подготовка учителя технологии и предпринимательства на основе интеграции содержания обучения. - Иркутск: Изд-во Иркут. гос. пед. ун-та, 2005. - 186 с.

25. Пузанкова Е.Н., Бочкова Н.В. Современная педагогическая интеграция, ее характеристики // Образование и общество. - 2009. - № 1. - С. 9-13. 
26. Арташкина Т.А. Основные стратегические направления интегративной науки об образовании // Профессиональное образование в современном мире. - 2015. - № 2 (17). - С. 5-22.

27. Тимошенко А.И., Карелина Н.А. Структура и содержание интегративной образовательной среды техникума // Современные тенденции развития профессионального образования. - 2016. - № 3 (23). C. 93-97.

28. Зеер Э.Ф. Психология профессионального образования: учебник. - М.: Академия, 2009. - 384 с.

29. Matovu M. Education dualism and secularism: an integrated education approach to the education system in Uganda // International Journal for Educational Studies. - 2013. - № 5 (2). - P. 117-132.

30. McKeown S. Integrated education in Northern Ireland: education for peace? // Eds. M. Seedat, S. Suffla, D.J. Christie // Enlarging the Scope of Peace Psychology: African and World- Regional Contributions. US: Springer, 2017. - P. 75-92.

31. Frick T.W. The theory of Totally Integrated Education (TIE). URL: https://www.researchgate.net/ publication/321327429_The_Theory_of_Totally_Integrated_Education_TIE (дата обращения 10.05.2019).

Поступила 16.10.2019 г. 
UDC 37.012(47+57)(100)

\title{
RESOURCES OF INTEGRAL APPROACHES IN THE AREA OF EDUCATION IN RUSSIA AND ABROAD
}

\author{
Marina I. Gaskova, \\ mia78988@gmail.com
}
Institute of Economics and Industrial Engineering, Siberian Branch of the Russian Academy of Sciences,
17, Academician Lavrentyev avenue, Novosibirsk, 630090, Russia. Marina I. Gaskova, Cand. Sc., researcher, Institute of Economics and Industrial Engineering, Siberian
Branch of the Russian Academy of Sciences.

The relevance of the study is caused by the fact that integral theory and integral education are new areas that have been developing during the latest decades. For this reason, lack of cooperation of researchers is generally observed, and Russian scientists working in this field are most often unknown in the West. The significance of the article lies in an attempt to overcome fragmentation of knowledge - both scientific knowledge, formed by the worldview of classical science, and the modern education system with its disciplinary fragmentation, which does not contribute not only to formation of a holistic picture, but also to harmonious development of a healthy person. The aim of the study was to generalize and analyze the main approaches in the field of integrated education that currently exist in the world. The methods of analysis, synthesis, classification, and comparative research were used. The paper introduces the «map», which systematizes the main approaches (presented by both individual researchers and organizations) in the world, highlights key features, strengths and weaknesses, the main sources in development of approaches, and touches on aspects of teaching methods and methodology. Findings. Integrated education touches on the deep, essential foundations in understanding the learning process. It contributes to the revision of the main idea that makes up the content of traditional education, which can be formulated as "from information to transformation». That is, creation of the conditions for transformation of a human personality in his/her entirety rather than formal "pumping» of information from a teacher's to a student's head. The student is no longer viewed as a passive «recipient» of knowledge, but he is actively involved in the process to develop not only intellectual (rational), but also his value-spiritual, emotional and social functions, to form an active civic position, which implies helping one's neighbor and taking care of the environment. Integral education implies mutual development of a teacher and a student; it recognizes the existence of a variety of personalities of students and teachers (teaching styles, personality types, pedagogical styles, etc.). From a universal human point of view, it seeks to promote intercultural, interracial and interreligious understanding and dialogue; recognition of the ideological diversity and unity of mankind; an essential equality of all races.

Key words: Integral theory, types of education in the world, system holism, development and personal development, development of a whole personality.

The research was carried out within the state task of the Federal Agency for Scientific Organizations in Russia by the project XI.179.1.2. "Conditions and stimulus of forming and implementing population human potential in labor and education spheres» no. AAAA-A17-117022250119-3. 


\section{REFERENCES}

1. Tarasevich V. Postneklassicheskiy vyzov fundamentalnoy nauke [Postnonclassical challenge to fundamental science]. Voprosy ekonomiki, 2004, no. 4, pp. 107-117.

2. Bertolin J. Higher education and development in the knowledge society: from integral education to substantial positive externalities. Higher Education for the Future, 2018, vol. 5 (2), pp. 122-141.

3. Esbjörn-Hargens S. Integral teacher, integral students, integral classroom: applying integral theory to education. Available at: http://nextstepintegral.org/wp-content/uploads/2011/04/Integral-Education-EsbjornHargens.pdf (accessed 14 May 2019).

4. Obolkina S.V. Ontologisheskaya grammatika kholizma kak filosofskaya problema. Avtoref. Kand. nauk [Ontological grammar of holism as a philosophical problem. Cand. Diss.]. Ekaterinburg, 2005. 26 p.

5. Astin A., Reams J. Spirituality and integral thought in higher education. Integral Education. New Directions for Higher Learning. Eds. S. Esbjörn-Hargens, J. Reams, O. Gunnlaugson. New York, SUNY Press, 2010, pp. 331-344.

6. Chaudhuri H. The evolution of integral consciousness. Wheaton, Ill., Theosophical Pub. House, 1977. $140 \mathrm{p}$.

7. Ryan J. The complete yoga: the lineage of integral education. Integral Education. New Directions for Higher Learning. Ed. by S. Esbjörn-Hargens, J. Reams, O. Gunnlaugson. New York, SUNY Press, 2010. pp. 47-56.

8. Gunnlaugson O. Opening up the path of integral education. Integral Education. New Directions for Higher Learning. Ed. by S. Esbjörn-Hargens, J. Reams, O. Gunnlaugson. New York, SUNY Press, 2010. pp. 303-316.

9. Esbjörn-Hargens S., Reams J., Gunnlaugson O. The emergence and characteristics of integral education: an Introduction. Integral Education. New Directions for Higher Learning. Eds. S. Esbjörn-Hargens, J. Reams, O. Gunnlaugson. New York, SUNY Press, 2010. pp. 1-16.

10. Molz M. Contemporary integral education research: a transnational and transparadigmatic overview. Integral Education. New Directions for Higher Learning. Eds. S. Esbjörn-Hargens, J. Reams, O. Gunnlaugson. New York, SUNY Press, 2010. pp. 317-330.

11. Ferrer J., Romero M., Albareda R. Integral transformative education: a participatory proposal. Integral Education. New Directions for Higher Learning. Eds. S. Esbjörn-Hargens, J. Reams, O. Gunnlaugson. New York, SUNY Press, 2010. pp. 79-104.

12. Hocking B., Haskell J., Linds W. Unfolding bodymind: exploring possibility through education. Rutland, VT, Foundation for Educational Renewal, 2001. 180 p.

13. New directions in education: selections from holistic education review. Ed. by R. Miller. Brandon, VT, Holistic Education Press, 1991. 365 p.

14. Nussbaum M.C. Not for profit: why democracy needs the humanities. Princeton, NJ, Princeton University Press, 2016. 192 p.

15. Torosyan R. Teaching integratively: five dimensions of transformation. Integral Education. New Directions for Higher Learning. Eds. S. Esbjörn-Hargens, J. Reams, O. Gunnlaugson. New York, SUNY Press, 2010. pp. 27-148.

16. Jacoby B. Service-learning in higher education: concepts and practices. San Francisco, Jossey-Bass, 1996. $416 \mathrm{p}$.

17. Kabrin V.I. Transkommunikativnye osnovaniya analiza tsennostnogo mira cheloveka [Transcommunicative bases of analysis of human values]. Tsennostnye osnovaniya psihologicheskoy nauki i psihologiya tsennostey [Value foundations of psychological science and psychology of values]. Eds. V.V. Znakov, G.V. Zalevskiy. Moscow, Institut psihologii RAS Publ., 2008. pp. 186-215.

18. Esbjörn-Hargens S. Integral theory in service of enacting integral education: illustrations from an online graduate program. Integral Education. New Directions for Higher Learning. Eds. S. Esbjörn-Hargens, J. Reams, O. Gunnlaugson. New York, SUNY Press, 2010. pp. 57-78.

19. Participatory research methods. Available at: http://participatesdgs.org/methods/ (accessed 8 July 2019).

20. Participatory action research. Wikipedia. Available at: https://en.wikipedia.org/wiki/ Participatory_action_research\#cite_note-ChevalierBuckles2013-2 (accessed 8 July 2019).

21. Nordwall S. What studies have been published on Waldorf education? 2006. Available at: www.waldorfresearchinstitute.org/pdf/RCWaldorfRes.pdf (accessed 08 July 2019).

22. Waldorf Education. Wikipedia. Available at: https://en.wikipedia.org/wiki/Waldorf_education (accessed 10 July 2019).

23. Strelnikov P.A., Znikina L.S. The principles of the system-functional development in integrative educational processes. Bulletin of Kemerovo State University, 2017, no. 4, pp. 41-44. In Rus. 
24. Timoshenko A.I. Podgotovka uchitelya tekhnologii i predprinimatelstva na osnove integratsii soderzhaniya obucheniya [Training technology and business teachers on the basis of integration of educational content]. Irkutsk, Irkutsk State Pedagogical University Publ., 2005. 186 p.

25. Puzankova E.N., Bochkova N.V. Sovremennaya pedagogicheskaya integratsiya, ee kharakteristiki [Modern pedagogical integration, its characteristics]. Obrazovaniye i obshchestvo, 2009, no. 1, pp. 9-13.

26. Artashkina T.A. The main strategic trends in integrative educational science. Professional education in the modern world, 2015, no. 2 (17), pp. 5-22. In Rus.

27. Timoshenko A.I., Karelina N.A. Struktura i soderzhaniye integrativnoy obrazovatelnoy sredy tekhnikuma [The structure and content of integrative educational environment of a college]. Sovremennye tendentsii razvitiya professionalnogo obrazovaniya, 2016, no. 3 (23), pp. 93-97.

28. Zeer E.F. Psikhologiya professionalnogo obrazovaniya [Psychology of professional education]. Moscow, Akademiya Publ., 2009. 384 p.

29. Matovu M. Education dualism and secularism: an integrated education approach to the education system in Uganda. International Journal for Educational Studies, 2013, no. 5 (2), pp. 117-132.

30. McKeown S. Integrated education in Northern Ireland: education for peace? Eds. M. Seedat, S. Suffla, D.J. Christie. Enlarging the Scope of Peace Psychology: African and World-Regional Contributions. US, Springer, 2017. pp. 75-92.

31. Frick T.W. The theory of Totally Integrated Education (TIE). 2017. Available at: https://www.researchgate. net/publication/321327429_The_Theory_of_Totally_Integrated_Education_TIE (accessed 10 May 2019).

Received: 16 October 2019. 